\title{
INVESTIGACIÓN
}

Recibido: 09/02/2016 --- Aceptado: 22/04/2016 --- Publicado: 15/06/2017

\section{ARTURO USLAR PIETRI Y SUS EDITORES}

Arturo Uslar Pietri and his publishers

Laura Febres: Universidad Metropolitana. Venezuela

$\underline{\text { lfebres@unimet.edu.ve }}$

\section{RESUMEN}

En la Casa de Estudio de la Historia de Venezuela, Lorenzo A. Mendoza Quintero, se encuentra el archivo de la correspondencia de Arturo Uslar Pietri. En este trabajo analizaremos de esa gran cantidad de cartas, solo aquellas que tienen relación con sus editores. Estas cartas se encuentran fechadas entre 1946 y 1984, años en los cuales Uslar Pietri mantuvo contacto con las editoriales para la publicación de sus obras. Buena parte de estas cartas provienen de la caja número 060.001-060044 carpeta 060.011 que lleva por título Editorial Losada, otras de su epistolario con figuras importantes del mundo editorial como Guillermo De Torre y Carmen Ballcells. Pero también con autores que publicaban junto con él quienes compartían las experiencias de este proceso como Miguel Ángel Asturias y Luis Beltrán Guerrero. Nuestro objetivo con este trabajo es comunicar la importancia que tiene el mercado editorial para la difusión de la obra de los autores latinoamericanos y hemos tomado el caso concreto de Arturo Uslar Pietri porque contamos con la documentación necesaria para hacer un análisis de parte de esta trayectoria, circunstancia que no es a veces posible con otros autores porque no se guardó la documentación necesaria para hacer un estudio con esta temática. La conclusión a que llegamos es que aunque estamos hablando de un autor con un gran prestigio intelectual nacional e internacional, tuvo problemas con sus editoriales que generalmente no eran puntuales en cancelarle sus honorarios. Sin embargo, también escuchamos las voces de los editores, como la de Gonzalo Losada por medio de las cuales observamos que el trabajo de las editoriales en Latinoamérica no está exento de riegos legales y económicos que expondremos en este trabajo.

\section{PALABRAS CLAVE}

Editoriales - Argentina - España - Latinoamérica - Siglo XX 


\begin{abstract}
In the House of Study of Venezuelan History: Lorenzo A. Mendoza Quintero, the correspondence file of Arturo Uslar Pietri is found. In this paper we will analyze, out of that big amount of letters, only those which are related to his publishers. These letters have been dated between 1946 and 1984, times in which Arturo Uslar Pietri held contact with the publishing houses for the publication of his works. A great quantity of these letters comes from the box No. 060,001 to 060,044, folder 060,011 which is titled "Losada Editorial", others come from his epistolary with important characters of the publishing world, such as Guillermo De Torre: and Carmen Ballcells, but also with authors who published together with him and shared the experiences of this process, like Miguel Angel Asturias and Luis Beltran Guerrero. Our objective with this research is to communicate the importance that the book market has for the diffusion of the works of the Latin American authors, and we have taken the concrete case of Arturo Uslar Pietri because we have the necessary documentation to make an analysis of part de this trajectory. This, sometimes, is not possible with other authors, since the required records to make a study with this subject matter were not kept. The conclusion that we came to, is that even though we are talking about an author with great national and international intellectual prestige, he struggled with his publishing houses, which were generally not punctual when it came to the payment of his work. Nonetheless, we also heard the voices of the publishers, such as Gonzalo Losada: through whom we observed that the work of the publishing houses of Latin America is not safe from the legal and economic risks which will be presented in this work.
\end{abstract}

\title{
KEYWORDS
}

Publishing houses - Argentine - Spain - Latin America - XX Century.

\section{ARTURO USLAR PIETRI E SEUS EDITORES}

\section{RESUMO}

$\mathrm{Na}$ Casa de Estudos da História de Venezuela, Lorenzo A. Mendoza Quintero encontra-se o arquivo da correspondência de Arturo Uslar Pietri. Neste trabalho analisaremos desta grande quantidade de cartas, somente aquelas que têm relação com seus editores. Estas cartas datadas entre 1946 e 1984, anos nos quais Uslar Pietri manteve contato com as editoras para a publicação de suas obras. Boa parte destas cartas provem da caixa numero 060.001-060044 pasta 060.011 que leva como titulo Editorial Losada, outras de seu epistolário com figuras importantes do mundo editorial como Guillermo De Torre y Carmen Ballcells. Mas também com autores que publicavam junto com os que compartiam as experiências de este processo como Miguel Angel Astúrias e Luis Beltran Guerrero. Nosso objetivo com esse trabalho é comunicar a importância quem tem o mercado editorial para a difusão da obra dos autores latino-americanos e tomamos o caso concreto de Arturo Uslar Pietri porque 
contamos com a documentação necessária fazer uma analise de parte desta trajetória, circunstância que nem sempre é possível com outros autores, porque não foi guardada a documentação necessária para um estudo desta temática. A conclusão que chegamos é que apesar estarmos falando de um autor com grande prestígio intelectual nacional e internacional, teve problemas com suas editoras que geralmente não eram pontuais pagando seus honorários. Não obstante, escutamos as vozes dos editores, como a de Gonzalo Losada por meio das quais observamos que o trabalho das editoras em Latino-america não está isento de riscos legais e econômicos que exporemos neste trabalho.

\section{PALAVRAS CHAVE}

Editoras - Argentina - Espanha - Latino-américa - Século XX

\section{Cómo citar este artículo}

Febres, L. (2017). Arturo Uslar Pietri y sus editores [Arturo Uslar Pietri and his publishers] Vivat academia, revista de comunicación, 139, 67-81. doi: https://doi.org/10.15178/va.2017.139.67-81

Recuperado de http:/ / www.vivatacademia.net/index.php/vivat/article/view / 609

\section{INTRODUCCIÓN}

Para un intelectual la mediación con el mundo editorial es básica para la comunicación con su público, por lo menos hasta finales del siglo XX, cuando aún Internet no ocupaba tanto el tiempo de los lectores. Este es el caso de Arturo Uslar Pietri y su relación con la Editorial Losada ubicada por mucho tiempo en Buenos Aires que estudiaremos en este trabajo. Le recordaremos que recientemente se cumplieron 75 años de la fundación de esta editorial tan importante para la distribución del libro en Latinoamérica.

La correspondencia consultada que abarca hasta el año de 1984, nos exigió también comunicar los resultados del contacto de Uslar Pietri con otras editoriales que expresaremos aquí, porque no modifica sustancialmente el comportamiento de las editoriales con el autor.

La carpeta donde se encuentra buena parte de la información es la número 060.011 y se encuentra dividida en dos partes, la primera contiene cartas fechadas entre 1946 y 1960 y la segunda, entre 1961 y 1984. Las otras cartas que conseguimos con respecto dirigidas a otros destinatarios se encuentran en otras carpetas diferentes. El año final de nuestra consulta no fue fijado por ninguna lógica perteneciente al problema aquí tratado, sino a que no registramos cartas clasificadas del autor después de esa fecha en el Archivo de la Casa de Estudio de la Historia de Venezuela, Lorenzo A. Mendoza Quintero que fue donde realizamos la mayor parte de la investigación de Archivo. 


\section{DISCUSIÓN}

\subsection{Arturo Uslar Pietri y Argentina}

Las relaciones de Uslar Pietri con la editorial Losada pueden ser precedidas por unas breves palabras que muestren el lazo que tuvo el autor venezolano con ese país. Cuando el 18 de octubre de 1945 tuvo que caminar la senda del exilio tan frecuente para muchos latinoamericanos en toda nuestra historia. No dejó de recibir invitaciones para continuar en Argentina su labor intelectual. Como la que escucharemos a continuación:

$\mathrm{Vd}$. se imagina el placer que me causaría su radicación entre nosotros. Francamente no sé qué decirle en cuanto a la consulta que me formula. Estoy seguro que un hombre de sus altas cualidades intelectuales podría muy bien desarrollar actividades beneficiosas para Vd. y para nosotros. Muchos colegas extranjeros, aun cuando en este caso no sería un extranjero $\mathrm{Vd}$. entre nosotros, ocupan posiciones profesionales o desarrollan actividades en empresas editoriales muy importantes. Aita, Antonio. Archivo Arturo Uslar Pietri. Caja 10. Carpeta 44.

Este interés de Arturo Uslar por Argentina podría ser debido a la presencia de escritores, editoriales e imprentas que podrían facilitar su trabajo. A pesar de las ofertas, decide ir a New York, ciudad en la cual trabajaría desde 1946 en la Universidad de Columbia, en el Departamento de Español. (Arraiz, 2005: 220-221).

Este exilio que pudiera haberse convertido en una experiencia traumática para Arturo Uslar Pietri, resultó sumamente fructífero para la literatura lo que hace exclamar a Luis Beltrán Guerrero: “Sin duda, eres más grande en la desgracia que en el éxito. Lo disfruto, como amigo, de tu gloria, verdaderamente, cincelada ahora en el destierro y con el dolor." Guerrero, Luis. B. 31/07/1947. Archivo Arturo Uslar Pietri. Caja 80. Carpeta 218.

Más tarde, el primero de noviembre de 1961, Gonzalo Losada demostrará en esta correspondencia su admiración por la obra literaria de Arturo Uslar Pietri, expresando lo siguiente: "Espero con interés y curiosidad los originales de su nueva obra UN RETRATO EN LA GEOGRAFÍA y desde ahora le auguro un gran éxito pues usted es un hombre que sabe contar cosas interesantes con consumado arte de escritor." Archivo Arturo Uslar Pietri. Caja número 060.001-060044 carpeta 060.011. La presencia Argentina en la obra de Uslar Pietri se deja sentir en artículos sobre algunos de sus más grandes creadores, como Domingo Faustino Sarmiento, Leopoldo Lugones y Jorge Luis Borges. También la obra intelectual de Uslar Pietri es comentada con frecuencia por los argentinos en el diario La Nación de Buenos Aires como aparece en los estudios hemerográficos que se han hecho sobre él.

Muchos más tarde en la época de la crisis argentina en su libro Golpe y estado en Venezuela, en un artículo titulado "La visión pesimista de la América Latina" publicado en 1989, nos transcribe brillantemente la opinión de los argentinos entrevistados por Naipaul para un trabajo publicado por The New York Review of 
Books en el cual ellos afirman que su país no era viable. La opinión de Uslar Pietri es totalmente contraria:

Para fines del siglo XVIII la Argentina era uno de los países más promisorios y deseados por los imperialismos europeos. Los hombres que hicieron la independencia lo creían viable y lucharon heroicamente por un proyecto que no tenía término visible. Lo mismo pensaron Albertí, Sarmiento o Mitre y los hombres que, desde fines del siglo XIX, convirtieron aquel país en uno de los mejores ejemplos de crecimiento. Los poetas modernistas, en 1910, pudieron celebrar con mucho énfasis afirmativo el centenario de la independencia como la culminación de una gran jornada de creación, que se prolongaría indefinidamente en el tiempo para convertir a la Argentina en uno de los más prósperos países del mundo. El tono entusiasta con que celebraron la fecha grandes poetas, como Ruben Darío o Leopoldo Lugones, no deja dudas. No solamente la Argentina les pareció viable, sino prodigiosamente llena de promesas de futuro. Uslar, 1989: 117

\subsection{Arturo Uslar Pietri y la Editorial Losada}

La correspondencia de Arturo Uslar Pietri y la Editorial Losada consultada se encuentra en el Centro de Documentación y Archivo de la Casa de Estudio de la Historia de Venezuela Lorenzo A. Mendoza Quintero como ya dijimos.

Aunque la índole de la correspondencia es sobre todo administrativa, constata la importancia que tiene el aspecto editorial en la publicación de las obras de nuestros autores, como es el caso concreto de Arturo Uslar Pietri que vamos a tratar aquí. La historia del trabajo editorial no ha sido muy tenida en cuenta dentro de la historia intelectual de América Latina aunque, a nuestro juicio, ha tenido un papel capital en el desarrollo de nuestra cultura y en la unión de la cultura latinoamericana, es por esto que quisimos contribuir con este pequeño aporte contenido en este trabajo.

Para tener una idea de la importancia temporal y material de las relaciones de Arturo Uslar Pietri con esta editorial pasaremos a citar un párrafo del mismo autor que la describe:

Como usted bien sabe, la Editorial Losada de Buenos Aires publica Las Lanzas coloradas periódicamente desde hace una treintena de años. Por los ejemplares que recibo veo en la justificación de tiraje que están haciendo ediciones semestrales de 15 a 20.000 ejemplares, es decir, más de 30.000 ejemplares anuales. Archivo Arturo Uslar Pietri. Caja número 060.001-060044 carpeta 060.011. 4/07/1984.

En el año 2013 la editorial Losada, fundada el 18 de Agosto de 1938, cumplió 75 años. En este trabajo se recuerda una fecha tan especial. Entre sus fundadores figuraron Guillermo de Torre, Felipe Jiménez de Asúa, Atilio Rossi, Amado Alonso, el dominicano Pedro Henríquez Ureña y Francisco Romero.

http://elpais.com/diario/2002/04/13/cultura/1018648803_850215.html: “Después de Calpe1, o al igual que ella, LOSADA es la editorial de más nombre. Es, por otra parte, la editorial liberal. Calpe, la reaccionaria. De modo que no se debía ir a otra

$1 \quad$ La Espasa Calpe era también una editorial muy importante en los años que venimos tratando. 
editorial." Guerrero, Luis. B. 31/07/1947. Archivo Arturo Uslar Pietri. Caja 80. Carpeta 218.

Coincide su fundación con el inicio de lo que será una de las década más importantes de la producción del libro argentino, la década de los cuarenta, porque debido a la situación bélica de Europa se trasladó a esta capital la mayor producción de libros en lengua española. Por eso los fundadores de ella no fueron solamente argentinos. En el párrafo anterior se hace hincapié en la procedencia caribeña de Pedro Henríquez Ureña (1894-1946) y en su fundador Gonzalo Losada (1894-1981) quien era madrileño de origen gallego. También es importante destacar que estos dos personajes tuvieron un vínculo generacional ya que ambos nacieron en el mismo año.

El clima intelectual que se respiraba en Buenos Aires atrajo por lo menos a dos venezolanos destacados que trabajaron parte de su obra en ese país, como fueron el músico Juan Vicente Lecuna y el historiador, poeta y crítico literario Luis Beltrán Guerrero. Ambos frecuentaron a Gonzalo Losada como queda registrado en la correspondencia que este último autor le dirige desde Buenos Aires a Arturo Uslar Pietri.

Mañana se reunirá la Comisión (Romero, Albertí, Guillermo de Torre, etc.), y de larga conversación que hoy tuve con Gonzalo Losada (a quien de antiguo conocía por presentación de Pedro Henríquez Ureña, y había tratado después casa de Juan Vicente Lecuna), deduzco que los asesores que han leído el libro tienen de él el mejor juicio, que "se ha puesto un pica en Flandes" (expresión de Losada) ... ${ }^{2}$ Guerrero, Luis. B. 31/07/1947. Archivo Arturo Uslar Pietri. Caja 80. Carpeta 218.

También deja testimonio Luis Beltrán Guerrero del clima intelectual en Buenos Aires por aquellos años donde se celebraban eventos a los cuales acudían figuras como las que señala en la siguiente reseña:

El domingo se verificó un estupendo FESTIVAL DE LA POESÍA, con la presencia de Pablo Neruda, Rafael Albertí, Nicolás Guillen, León Felipe, González Carbalho, Rafael Dieste y Alejandro Casona. Neruda recitó, entre otros poemas, el dedicado a Bolívar. Guerrero, Luis. B. 31/07/1947. Archivo Arturo Uslar Pietri. Caja 80. Carpeta 218.

De todo este contacto intelectual y humano nace una buena relación entre Arturo Uslar Pietri y la editorial Losada que culmina en la publicación de los siguientes libros:

El Camino de El Dorado (1947), Las Lanzas Coloradas (1948), Treinta hombres y sus sombras (1949), La ciudad de nadie. El otoño en Europa. Un turista en el cercano Oriente (1960), Un retrato en la geografía. El Laberinto de Fortuna (1962), Estación de Máscaras. El laberinto de Fortuna (1964).

En las primeras cartas después de la firma del contrato para la publicación de "El Camino de El Dorado", se evidencian las dificultades para la publicación y distribución de libros en Latinoamérica durante este periodo. Estas circunstancias también afectan la reedición de Las Lanzas Coloradas y la publicación de Treinta Hombres y sus sombras, incluso se prolongan y agudizan, al punto que dificultan el pago a Uslar de sus

2 Se reunirán entre otras cosas para tomar una decisión con respecto a la publicación de El camino de El Dorado 
derechos de autor debido a los problemas para encontrar divisas extranjeras en Argentina.

Según lo expresado por Gonzalo Losada estas dificultades editoriales que produjeron un gran retraso en la publicación de las obras de Uslar, fueron ajenas a la editorial y a la voluntad misma de Losada, más bien fueron de carácter común en Latinoamérica, según lo expresado en una carta del 16 de febrero de 1949.

Estas dificultades no afectaron las relaciones entre Uslar y la editorial, debido al gran afecto que lo vinculaba a su fundador que puede ser observado en la correspondencia muchas veces del cual sólo es muestra el siguiente párrafo:

Espero con interés y curiosidad los originales de su nueva obra UN RETRATO EN LA GEOGRAFÍA y desde ahora le auguro un gran éxito pues usted es un hombre que sabe contar cosas interesantes con consumado arte de escritor. Caja número 060.001-060044 carpeta 060.011, 11/01/1961

Junto a estas expresiones de admiración, Gonzalo Losada expresa en las cartas valoraciones acerca de su percepción del mercado editorial que pueden ser de ayuda para todos aquellos que enfrenten este mercado:

Si la novela interesa y a mí no me cabe la menor duda de que va a interesar, se venderá aunque es posible que su precio reduzca algo sus posibilidades de circulación pero no las anulará de ninguna manera.

Pero la realidad es la realidad que demuestra que el negocio editorial no es ni tan sencillo ni tan lucrativo como la gente cree.

En cambio el distribuidor y el librero que no crean como el autor ni arriesgan como el editor se llevan hasta el $50 \%$ del precio marcado al libro más los recargos que suelen establecer en la conversión. Caja número 060.001-060044 carpeta $060.011,10 / 11 / 61$

Junto con los riesgos económicos que corre el editor, se encuentran los riegos legales. Entre los tópicos más importantes de este tipo, figura la lucha por la libertad de expresión que libra la Editorial Losada por publicar una novela titulada El reposo del guerrero de Christiane Rochefort la que consideró un Juez argentino que iba contra las buenas costumbres del país:

...diré a usted que se ha levantado un movimiento nacional de protesta que ha tenido su expresión en diarios, revistas, televisión, radio y, por último, en el banquete de homenaje, que yo acepté porque el asunto supera mucho lo estrechamente personal, que ha sido uno de los acontecimientos más importantes de la vida intelectual y política de la Argentina. No es posible permanecer silenciosos ante estos solapados ataques que se dirigen directamente a cohibir la libertad de expresión, haciendo que los propios editores, empresarios teatrales etc., seamos los que establezcamos la censura, es decir, una auto-censura, ya que las leyes del país no permiten aquella. Caja número 060.001-060044 carpeta 060.011, 5/07/1961.

Y continúa el mes siguiente:

En mayo de 1961, la justicia se expidió condenando al Sr. Gonzalo Losada, editor, y al Sr. Luis Amibilia, traductor, a uno y seis meses de prisión respectivamente. Esta medida no tiene precedentes en la Argentina y provocó 
manifestaciones de indignación y alarma como declaraciones de la SADE (Sociedad argentina de Escritores). Mensajes de solidaridad llegaron a la Editorial Losada desde el mundo. Caja número 060.001-060044 carpeta 060.011.

La contestación de Arturo Uslar Pietri se dará el 18 de Julio de 1961: "Parece mentira que a estas alturas, (...) un juez argentino tenga la peregrina ocurrencia de enviarle a usted a la cárcel por publicar El reposo del Guerrero." Caja número 060.001-060044 carpeta 060.011.

El día 13 de julio de 1979 Arturo Uslar Pietri le emite un memorando a la Señora Carmen Balcells comunicándole cuáles de sus libros son los editados por la Editorial Losada: El camino de El Dorado, Las Lanzas Coloradas, El laberinto de la Fortuna, La ciudad de nadie y 30 hombres y sus sombras.

No tuvo la editorial Losada la absoluta exclusividad sobre toda la obra de Uslar Pietri quien fue editado por una editorial tan famosa como Taurus en 1966 donde publica su libro Pasos y Pasajeros y el 13 de noviembre de 1980, afirma: "Hace algunos años cedí los derechos de mi libro "La otra América" a la Alianza Editorial."

\subsection{Un final poco feliz con la editorial Losada}

El estudio de las relaciones afectivas y comerciales de Arturo Uslar Pietri con la editorial Losada que expresaremos aquí, pueden ser una muestra de cómo se manejan, en ciertos casos, las relaciones entre editores y autores en el continente americano. Para ello tenemos que tener en cuenta que Arturo Uslar Pietri no representa a la mayoría de los autores de nuestro continente porque el tiraje de sus obras es muy grande en relación al que usualmente se editan de nuestros autores en Latinoamérica. Sin embargo, su estatura no lo protege inicialmente de las jugarretas de su editor quien finalmente accede a pagarle el precio justo, después de sus reclamos acertados.

El primer desencuentro surge en torno a la novela El camino de El Dorado cuya primera edición sale en 1947, ya que este autor considera que la editorial no le ha prestado la suficiente atención editorial y se ha concentrado solamente en promocionar su novela Las Lanzas coloradas que Gonzalo Losada piensa que "es una de las perlas de nuestro catálogo." Caja número 060.001-060044 carpeta 060.011, 13/09/1977.

El 10 de octubre de 1977, Arturo Uslar Pietri le escribe a la editorial Losada:

Por una elemental lógica de ventas, un libro con buena demanda sirve de locomotora para arrastrar los otros del mismo autor. Tal vez ha faltado un poco promoción en este sentido, particularmente en lo que se refiere a EL CAMINO DE EL DORADO. Caja número 060.001-060044 carpeta 060.011.

A partir del año 1979 empiezan a observarse el deterioro de las relaciones comerciales y personales entre la Editorial Losada y Arturo Uslar Pietri quien constantemente se queja de que no ha recibido el pago justo por la venta de sus libros y de la ausencia de su fundador Gonzalo Losada. Este mismo año le comunica a la 
editorial que ha sido encargada Carmen Balcells. ${ }^{3}$ "-Agencia Literaria de Barcelona, España, de todo lo relativo a mis relaciones de autor con los editores de mis libros. Ella realiza en este momento un examen de la situación de esas relaciones y, por lo tanto, se dirigirá a ustedes en mi representación". Caja número 060.001-060044 carpeta 060.011

En esa misma carta dirigida a la editorial Losada desde Caracas el 12 de julio de 1979 les recuerda lo siguiente: “Tengo muy viejas y buenas relaciones con la Editorial Losada desde por lo menos el año de 1947, y particularmente con su antiguo Presidente y propietario, señor Gonzalo Losada, mi excelente amigo." Caja número 060.001-060044 carpeta 060.011

Luego el 17 de abril de 1980 les escribe en su correspondencia: “No es sin pesar que por primera vez en tan largos años de relación tengo que entenderme con esa casa en términos estrictamente comerciales pero las circunstancias parecen llevarnos a ese terreno." Caja número 060.001-060044 carpeta 060.011

Ya para el 21 de octubre de 1981 Uslar Pietri plantea a la editorial Losada la necesidad de que su obra sea publicada y vendida por otras editoriales. El reclamo se inicia en torno a El camino de El Dorado: "Pero creo necesario autorizar a otros editores, fuera de Argentina, sin carácter de exclusividad, para hacer nuevas ediciones y en este sentido me he puesto de acuerdo con mi agente en Barcelona, la señora Carmen Balcells." Caja número 060.001-060044 carpeta 060.011.

La contestación de la editorial Losada no se hace esperar el 13 de noviembre de 1981, cederán para este proyecto los mercados de México y España, pero conservarán el resto de los países latinoamericanos:

Nos inclinamos a aceptar sin más su decisión, pero entendemos que debemos conservar la plaza latinoamericana en exclusividad, quedando los importantes mercados de España y México a compartir con las ediciones que usted estime oportuno autorizar. Caja número 060.001-060044 carpeta 060.011.

El 9 de julio de 1984 Arturo Uslar Pietri exclama: “...hace más de cinco años no recibo ningún estado de cuenta ni liquidación relativos a las obras mías que ustedes editan, lo que me preocupa y me causa sorpresa. (...) Yo soy acreedor de ustedes por una suma de bastante consideración". Caja número 060.001-060044 carpeta 060.011

El 25 de enero de 1983 le informa a la editorial Losada que quiere darle a la Señora Carmen Balcells toda la libertad necesaria para celebrar los contratos que considere pertinentes y necesarios para su obra y que por lo tanto no intervendrá en lo que a estos se refiere:

Recibí su amable carta del 11 del corriente en la que me comunican estar en trato con la señora Balcells para una nueva edición de El camino de El Dorado para España y México. Mucho me complace que puedan llegar a un acuerdo

3 En este momento le expreso al lector algunos datos de la biografía de Carmen Balcells, por si acaso desconoce la importancia de este personaje para el mercado del libro español y latinoamericano. Nacida en Santa Fe de Segarra, Lleida, en 1930. Concibió la relación autoreditor de otra manera, ya que peleaba por el reconocimiento de los derechos económicos del primero desde 1960 cuando entra en el mercado del libro. Tuvo un papel primordial en la edición y publicación del Boom latinoamericano. Desde 1979 Arturo Uslar Pietri la encarga de la comercialización de su obra como vemos en este trabajo.

http://www.biografiasyvidas.com/biografia/b/balcells.htm 
equitativo pues yo no quiero interferir en las gestiones que ella hace como mi representante. Caja número 060.001-060044 carpeta 060.011.

En correspondencia privada con Carmen Balcells el 9 de julio de 1984 expresa:

No recibo liquidaciones desde abril de 1979. Si tomamos en cuenta que han venido haciendo ediciones de alrededor de 30.000 ejemplares por año en este quinquenio pasado y que el precio convenido de venta es el equivalente a U.S \$ 4,00 por ejemplar, esto daría la suma de 150.000 ejemplares vendidos y de alrededor de U.S.\$ 600.000, lo que representa una acreencia mía por una suma muy respetable con respecto a esa casa. Caja número 020.001-020.057, Carpeta 020.010, 9/7/1984.

Para continuar el 20 de septiembre de 1984, con su reclamo a la editorial Losada:

Considero que en estas condiciones cesan para ustedes toda autorización de editar mis libros, además de reservarme las acciones legales que tenga derecho. Sinceramente lamento que las relaciones amistosas y leales que tuve con el fundador de esa casa Don Gonzalo Losada, hayan llegado a un fin tan lamentable. Caja número 060.001-060044 carpeta 060.011.

En correspondencia de 19 de octubre de 1984 ahonda Arturo Uslar Pietri sobre el problema en cuestión y podemos darnos una idea sobre el tiraje que alcanzaban las obras de Uslar Pietri en esa editorial:

Dicen ustedes que el pago que me anunciaron es sólo parte de la deuda y así lo entiendo, y que el monto total de lo que se me adeuda es de 580.042 pesos argentinos, que convertidos en dólares arroja la cifra de U.S. \$ 8.056. Esta cifra no corresponde a la realidad. Según facturaciones auténticas de libreros de Caracas, ustedes les cotizan el ejemplar de "Las lanzas coloradas" a U.S.\$2,20 el ejemplar, lo que sobre 60.000 ejemplares que es, según ustedes, la cifra total y final de ventas, arrojaría un ingreso de U.S.\$132.000. El 10\% de esta cantidad es, sin duda, U.S.\$13.200 lo que representa, según las cifras de ustedes, una diferencia contra mí de U.S:\$ 5.144. Caja número 060.001-060044 carpeta 060.011.

El 4 de diciembre de 1984 contamos con una carta dirigida por Arturo Uslar Pietri a la Señora Carmen Balcells donde se expresa que la editorial Losada va a cancelarle la cifra que le adeuda y que la encarga a ella del cierre de esta negociación:

Como usted verá, se vuelve un lío tratando de explicar lo que no tiene explicación, pero finalmente ofrece pagar la suma no despreciable de U.S.\$ 13.200. Pienso que lo prudente es asegurar este pago a la brevedad posible y luego proceder adelante con sus proyectos para la colocación de "Las lanzas coloradas". A Losada le he respondido avisándole recibo de su carta y diciéndole que le he enviado a usted para la debida tramitación. Caja número 020.001-020.057, Carpeta 020.010.

De esta forma culmina el inconveniente narrado que puede ser ilustrativo de las relaciones no siempre fáciles de los autores con los editores de sus obras en nuestro continente que intentó hacer más justas la agente literaria Carmen Balcells. 
La correspondencia de Uslar Pietri con la Editorial Losada continúa hasta el 4 de diciembre de 1984 en lo que hemos podido constatar, cuando Losada comparte los derechos de autor cedidos en un tiempo a esta editorial por Uslar Pietri con otras editoriales como Seix Barral, La Oveja Negra, Salvat y el Grupo de Armas.

\subsection{Arturo Uslar Pietri y Carmen Balcells}

A partir de junio de 1979, Arturo Uslar Pietri decide delegar la responsabilidad de la distribución y edición de sus libros a la Señora Carmen Balcells. El mismo le da el título de Señora a esta editora catalana, a través de toda su correspondencia. Esta decisión la toma porque:

... la editorial Losada ha dejado de ser propiedad de Gonzalo Losada, mi buen amigo, lo cual modifica enteramente mi relación con esa casa que está fundada sobre todo en mi vieja amistad personal con este excelente hombre. No sé quiénes son los nuevos propietarios pero, desde luego, mi relación ahora será meramente comercial y por lo tanto puedo reclamar muchas cosas que antes no hacía. Entre otras, el pago de derechos que se ha hecho siempre de un modo simbólico pues nunca pasan de anunciarme la cantidad de pesos argentinos inmobilizados que tienen a mi disposición pero que nunca llegan." Caja número 020.001-020.057, Carpeta 020.010, 18/06/1979

En esta parte del trabajo trataremos los contactos editoriales que estable Arturo Uslar Pietri a través de su correspondencia con Carmen Balcells. Pueden haber sido muchos más, pero estos son los que quedan registrados en esta correspondencia.

Sin duda la señora Carmen Balcells empieza a mover la obra de Arturo Uslar Pietri, ya casi un mes después de su designación, encontramos que ofrece el cuento Los ganadores a Seix Barral y Bruguera. De la misma manera empieza a ofrecer la obra de Arturo Uslar Pietri en otros ambientes como la televisión colombiana que ha llevado a la pantalla a través de la productora $\mathrm{RTI}^{4}$ el cuento La mala hora de García Márquez. Sobre la calidad de estos programas se pronuncia de la siguiente manera: "Ya produjeron, en esa serie, La Mala Hora de García Márquez. Es de muy buena calidad y esto me hace pensar que harían un film digno y bien hecho:" Caja número 020.001020.057, Carpeta 020.010, 27/06/1979

El 20 de marzo de 1981 llega la firma del contrato para la adaptación en televisión de sus cuentos: "EL PRÓJIMO, EL ENEMIGO, CAÍN Y NTA. SRA. DE LA BUENA MUERTE, y LA SEGUNDA MUERTE DE DON EMILIO."

Sobre la firma de este contrato Arturo Uslar Pietri opina:

En respuesta a lo que me trata en la carta hoy le envío un cable dando autorización para vender los derechos de 4 cuentos míos a la cadena de televisión colombiana R.T.I. Estoy de acuerdo con usted en que el pago es ridículamente bajo pero de todos modos lo he autorizado por el interés que para mí tiene la difusión. Caja número 020.001-020.057, Carpeta 020.010, 27/02/1981.

\footnotetext{
${ }^{4}$ RTI significa Radio y Televisión Interamericana
} 
Sin embargo, esta correspondencia no sólo expresa las dificultades que tiene con la editorial Losada sino también con otras editoriales como Seix-Barral:

Me gustaría que usted le reclamara un poco a Seix-Barral sobre la distribución de Fantasmas de dos mundos en España. Constantemente recibo informes de que es difícil conseguirlo en librerías, y tengo la impresión de que Seix-Barral, en el caso de mis libros, prefiere concentrarse en el mercado venezolano que es para ellos el más seguro y productivo y desde luego para mí no es lo que más me interesa. Caja número 020.001-020.057, Carpeta 020.010, 18/06/1979.

Ya en 1980 empiezan a discutirse de manera más concreta los derechos de autor de Uslar Pietri, como no se había hecho antes en esta correspondencia:

Tal como le digo en mi carta referente a Las Lanzas Coloradas, creo que es mucho más interesante para $\mathrm{Vd}$. quedar enteramente libre de compromiso alguno con Losada en lo que respecta al nuevo libro, aunque sea pagándole una parte de los derechos de LAS LANZAS.

A fin de agilizar los trámites de contrato con Seix Barral, se lo acompaño, en tres ejemplares, y si lo aprueba le ruego devolvérmelos los tres firmados. Verá que el contrato establece un anticipote US\$ 7000, ... a la firma, sobre royalties del 10\% hasta 20.000 ejemplares vendidos, del 12\% hasta 50.000 y del 15\% después.

La duración es de cinco años, para edición normal únicamente, es decir que los derechos de bolsillo quedan enteramente libres para su posible futura contratación. Caja número 020.001-020.057, Carpeta 020.010, 8/04/1980.

Cuando Uslar Pietri firmó los anteriores contratos con la editorial Losada no se ponía una fecha tope para su terminación, otros vientos soplaban ahora indiscutiblemente.

Sin embargo, aunque firma el contrato, no queda muy de acuerdo con los términos expresados.

El nuevo libro al cual se refiere Uslar Pietri en esta parte de su correspondencia es $L a$ isla de Róbinson con el cual esperaba vencer la resistencia del mercado internacional. Desde su correspondencia con la Editorial Losada ya citada, vemos el interés de Uslar Pietri por ubicar sus obras en este mercado: "Espero que La isla de Róbinson nos abra para ella y para otros libros las duras puertas de la edición internacional". Caja número 020.001-020.057, Carpeta 020.010, 29/04/1981

La correspondencia con Carmen Balcells gira en torno a la importancia que Uslar Pietri concede a su libro La isla de Róbinson sobre el cual nos expresa:

En una revista argentina que publicó la lista de best sellers en Buenos Aires, apareció hace unos 10 días La isla de Róbinson entre los 10 libros más leídos para ese momento. Yo tengo la convicción de que este es un libro de mucha importancia dentro de la literatura latinoamericana y que debería merecer el interés de los traductores a otras lenguas, pues en muchos aspectos constituye un testimonio casi único de nuestra cultura y de las características de este mundo tan peculiar al través de algunos grandes personajes históricos. Caja número 020.001-020.057, Carpeta 020.010, 23/03/1982. 
Sin embargo, sus relaciones con Seix Barral no son mejores que con la editorial Losada, pero por otras causas. Seix Barral se une con Planeta y parte de los inconvenientes con los libros de Uslar Pietri provienen de esa fusión:

“Tengo la impresión que, por lo menos en Venezuela, la fusión de Seix-Barral con Planeta no va a ser favorable para la primera. No tengo la impresión de que vayan a hacer mucha promoción a los libros de Seix-Barral y que estos van a quedar un poco como los parientes pobres de la casa" 30/07/1982. Caja número 020.001-020.057, Carpeta 020.010.

Un año después le dirige a una carta a la Editorial Seix-Barral que termina con las siguientes afirmaciones:

Las gestiones de la señora Carmen Balcells han sido igualmente infructuosas. Yo considero que lo que se ha hecho conmigo es grave y da directamente base para una demanda judicial en defensa de mis derechos e intereses. En caso de no obtener a la mayor brevedad una respuesta final y definitiva a este enojoso asunto, no me quedará otro camino que el del procedimiento judicial que no deseo. Caja número 020.001-020.057, Carpeta 020.010, 1/07/1983.

Sin embargo, después de esta fecha continúa escribiendo sobre la poca propaganda que a El camino de El dorado le ha dado Seix Barral.

Tengo la impresión de que hay un poco de descuido por parte de Seix-Barral en promover mis libros. Personas de mi amistad que visitaron la reciente Feria del Libro en Madrid me dicen que no vieron ni La Isla de Róbinson ni ninguno de los otros títulos. Valdría la pena reclamarle a estos señores para que tengan un poco más de interés. Caja número 020.001-020.057, Carpeta 020.010, 7/06/1984.

También trata sus contactos con otras editoriales como Alianza Editorial a la cual le cede los derechos de su libro La otra América la cual tampoco le cancela sus honorarios:

Los derechos de autor que deben montar en la actualidad algo más de 100.000 pesetas no me han sido abonados. Yo le agradeceré mucho que usted tome cartas en este asunto, tanto para obtener el pago como para lograr que el libro sea reeditado, pues entiendo que la edición se agotó. Caja número 020.001020.057, Carpeta 020.010, 13/11/ 1980.

En 1981 inicia también contactos con la editorial colombiana Interedit: "acabo de recibir ahora su carta de 22 de diciembre en la que me trata el proyecto de la editorial colombiana Interedit de publicar en fascículos ilustrados algunas novelas." Caja número 020.001-020.057, Carpeta 020.010, 16/01/1981

En 1983 recibe una oferta de la Editorial Salvat con la que tenía relaciones anteriores a este epistolario y por medio de la cual nos damos cuenta la cuantía de las ventas de una de las obras de Uslar Pietri en esta editorial:

Recibí su amable carta del 24 del corriente en la que me participa que la Editorial Salvat se propone volver a publicar la Biblioteca Básica e incluir de nuevo en ella mi novela Las lanzas coloradas. La primera vez, hacia 1974, fue un 
gran éxito y por las liquidaciones que me enviaron llegaron a vender 400.000 ejemplares. Caja número 020.001-020.057, Carpeta 020.010, 7/04/1983.

Las Lanzas Coloradas también va a ser publicada por la editorial La oveja negra y escribe a Carmen Balcells "Le estoy devolviendo firmado el contrato con La Oveja Negra para la edición de Las lanzas coloradas." Caja número 020.001-020.057, Carpeta 020.010, 23/03/1984

\section{CONCLUSIÓN}

La última carta que se refiere a esta editorial, nos habla sobre Las lanzas coloradas destinadas solamente a Venezuela: "He recibido su amable carta del 14 de noviembre último con la que me envía el proyecto de contrato con la Editorial Oveja Negra de Colombia para una edición de Las lanzas coloradas destinada a ser vendida en Venezuela. Caja número 020.001-020.057, Carpeta 020.010, 6/12/1984

Esta es la última carta que pudimos registrar en el Archivo de la Casa de Estudio de la Historia de Venezuela Lorenzo A. Mendoza Quintero. Recordamos al lector que todavía faltan diez y siete años hasta el 2001 cuando muere el autor tratado. No hemos analizado aquí los registros del comportamiento editorial de muchos de sus libros publicados en este último período de tiempo y de su última novela La visita en el tiempo publicada en 1990, año en que le es conferido el premio Príncipe de Asturias de las Letras.

No encontramos en ese archivo la evolución de todo el comportamiento editorial de la obra de Arturo Uslar Pietri, sin embargo esta muestra de correspondencia puede ser significativa del problema que tuvo un escritor de la estatura de Arturo Uslar Pietri para el cobro de sus derechos de autor. Este no fue solo con la Editorial Losada como mostramos en el apartado primero de este trabajo sino con otras editoriales como Aliaza editorial, Seix Barral y Planeta como hemos podido constatar a través de la correspondencia aquí analizada. Si esta situación de irrespeto al cumplimiento de los pagos se hace con el autor tratado, no creemos que la situación sea diferente con respecto a otros autores latinoamericanos.

\section{REFERENCIAS}

Archivo Arturo Uslar Pietri. Centro de Información, documentación y Archivo. Casa de Estudio de la Historia de Venezuela Lorenzo A. Mendoza Quintero.

Araujo, C. La histórica editorial argentina Losada se instala en España. http://elpais.com/diario/2002/04/13/cultura/1018648803_850215.html

Arráiz Lucca, R. (2005). Arturo Uslar Pietri, Antología cronológica. Caracas: Banco Provincial.

Balcells, C. Biografías y vidas. Recuperado de http://www.biografiasyvidas.com/biografia/b/balcells.htm. 
Dabusti, T.M. Trayectoria de Lorenzo Luzuriaga en Losada. Una editorial del exilio. Conicet. Recuperado http://institucional.us.es/revistas/contemporanea/9_10_II/art_7.pdf

Uslar Pietri, A. (1992) Golpe y estado en Venezuela. Santafé de Bogotá: Editorial Norma.

Reinoso, S. La editorial Losada festeja 75 años de resistencia y grandes autores. Recuperado de http://www.revistaenie.clarin.com/literatura/editorial-Losadafesteja-resistencia-grandes_0_991701093.html

Rivas Dugarte, R. A. (2001). Fuentes complementarias para el estudio de Arturo Uslar Pietri. Caracas: Fundación Centro de Estudios Latinoamericanos Rómulo Gallegos.

Rubio, J. "Atril y Lápiz" Blog de lecturas. Recuperado de http://atrilylapiz.blogspot.com/2012/04/el-reposo-del-guerrero-de-rochefort.html

VV.AA. Contribución a la biblio-hemerografía de Arturo Uslar Pietri. (1989). Caracas: Fundación Polar.

\section{AUTOR}

\section{Laura Febres}

Licenciada en Letras por la Universidad Católica Andrés Bello (Venezuela); magister scientarium en Literatura Latinoamericana Contemporánea por la Universidad Simón Bolívar, consiguiendo mención de honor con su tesis de grado Pedro Henríquez Ureña. Crítico de América. En el año 2000, recibe en la UCAB, el grado de doctor suma cum laude en Historia con su trabajo La Historia en Mario Briceño Iragorry. Profesora universitaria desde el año 1981 en la UCAB en las cátedras de Literatura Hispanoamericana, Literatura Venezolana e Historia de la Lingüística hasta 1988 y desde 1987 hasta hoy en la Universidad Metropolitana en el Departamento de Humanidades.

Editora de la Revista Anales de la Universidad Metropolitana, ha publicado un importante número de libros, monografías y ensayos para reconocidas editoriales, revistas y páginas Web.

https://orcid.org/0000-0001-7518-8130 